\title{
Brain Glycogen Decreases with Increased Periods of Wakefulness: Implications for Homeostatic Drive to Sleep
}

\author{
Jiming Kong, ${ }^{2}$ P. Nicolas Shepel, ${ }^{1,2}$ Clark P. Holden, ${ }^{1}$ Mirek Mackiewicz, ${ }^{3}$ Allan I. Pack, ${ }^{3}$ and \\ Jonathan D. Geiger ${ }^{1,2}$ \\ ${ }^{1}$ Department of Pharmacology and Therapeutics, ${ }^{2}$ Division of Neurovirology and Neurodegenerative Disorders, St. \\ Boniface Hospital Research Centre, University of Manitoba Faculty of Medicine, Winnipeg, Manitoba, R2H 2A6, Canada, \\ and ${ }^{3}$ Center for Sleep and Respiratory Neurobiology, University of Pennsylvania, Philadelphia, Pennsylvania 19104-4283
}

Sleep is thought to be restorative in function, but what is restored during sleep is unclear. Here we tested the hypothesis that increased periods of wakefulness will result in decreased levels of glycogen, the principal energy store in brain, and with recovery sleep levels of glycogen will be replenished, thus representing a homeostatic component of sleep drive. Using a high-energy focused microwave irradiation method to kill animals and thereby snap-inactivate glycogen-producing and -metabolizing enzymes, we determined, with accuracy and precision, levels of brain glycogen and showed these levels to decrease significantly by $\sim 40 \%$ in brains of rats deprived of sleep for 12 or $24 \mathrm{hr}$. Recovery sleep of $15 \mathrm{hr}$ duration after 12 $\mathrm{hr}$ of sleep deprivation reversed the decreases in glycogen.
Using a novel histochemical method to stain brain glycogen, we found glycogen to be concentrated in white matter; this finding was confirmed biochemically in white matter dissected from rats killed with microwave irradiation. Levels of glycogen, as determined histochemically, were significantly decreased in gray and white matter with sleep deprivation, and these decreases were reversed with recovery sleep. The observed decreases in levels of brain glycogen may be a consequence of increased wakefulness and/or a component integral to the homeostatic drive to sleep.

Key words: sleep drive; sleep deprivation; brain energy store; glycogen; astrocyte; white matter
Although the overall function of sleep has yet to be elucidated, it is known that sleep is restorative (Benington and Heller, 1995), especially in the brain (Horne, 1985; Franken et al., 1991; Drummond et al., 2000). Similar to other restorative behaviors such as eating, drinking, and thermoregulation, the homeostatic drive to sleep is highly regulated and is directly proportional to the length of prior wakefulness (Horne, 1985; Franken et al., 1991, 2001; Drummond et al., 2000; Hendricks et al., 2000; Shaw et al., 2000). However, presently unclear is the extent to which brain energy stores and specific neurotransmitter substances are involved in this physiologically important and evolutionarily conserved function.

Restoration of brain energy metabolism has been posited as a drive to sleep (Karnovsky et al., 1983; Benington and Heller, 1995). This hypothesis predicts that sleep drive is promoted by decreases in levels of brain glycogen, the largest energy store in brain (Magistretti and Pellerin, 1996; Wender et al., 2000), and that resulting from these decreases in glycogen would be accumulations of the sleep-promoting substance adenosine (Rainnie et al., 1994; Porkka Heiskanen et al., 1997, 2000; Basheer et al., 2001). Glycogen stores in the brain are small relative to the liver and, especially, muscle. Nevertheless, brain glycogen turns over rapidly (Pentreath and Kai-Kai, 1982; Swanson et al., 1989) and

Received Jan. 22, 2002; revised March 13, 2002; accepted March 18, 2002.

This research was supported by Operating Grants HL60287 from the National Heart, Lung, and Blood Institute and AG17628 from the National Institute on Aging. We thank Yvonne Shewchuk, Benjamin Singer, and Dr. Shan Zeng for excellent technical assistance.

Correspondence should be addressed to Dr. Jonathan D. Geiger, Division of Neurovirology and Neurodegenerative Disorders, St. Boniface Hospital Research Centre, R4046-351 Tache Avenue, Winnipeg, Manitoba, R2H 2A6, Canada. E-mail: geiger@cc.umanitoba.ca.

Copyright (C) 2002 Society for Neuroscience $\quad 0270-6474 / 02 / 225581-07 \$ 15.00 / 0$ contributes significantly to normal brain energy metabolism (Swanson, 1992; Magistretti and Pellerin, 1996, 1999; Wender et al., 2000). Brain glycogen is located almost entirely in astrocytes (Phelps, 1972; Koizumi, 1974), the most numerous cells in the brain, which are distributed throughout the brain but are most concentrated in fiber bundles and white matter (Savchenko et al., 2000; Sloane et al., 2000). Astrocytes use glycogen as a source of glucose, especially during transient increases in metabolic demand (Tsacopoulos and Magistretti, 1996; Magistretti et al., 1999). Indeed, astrocytic glycogen in vitro is degraded rapidly when glucose is withdrawn (Dringen et al., 1993) and glycogen falls rapidly in vivo during ischemia, with a time course that is closely related to the depletion of ATP and the accumulation of lactate (Swanson et al., 1989). Clearly, astrocytes are functionally and metabolically complex cells that are integral to brain function, and the glycogen stores within these cells may play roles important to physiological and pathophysiological states. However, this hypothesis has remained untested primarily because of technical difficulties in determining levels of brain glycogen with accuracy and precision.

Here, we tested hypotheses that glycogen is enriched in brain astrocytes and white matter, that glycogen levels decrease with increased wakefulness (sleep deprivation), and that sleepdeprivation-induced decreases in levels of glycogen are normalized with recovery sleep. In so doing, we provide evidence that the observed decreases in levels of brain glycogen may be a consequence of increased wakefulness and/or a component integral to the homeostatic drive to sleep.

\section{MATERIALS AND METHODS}

Materials. All chemicals, including amyloglucosidase, hexokinase, $\mathrm{NADP}^{+}$dependent glucose-6-phosphate dehydrogenase, NADP ${ }^{+}$, ATP, EDTA, 
$\mathrm{MgSO}_{4}$, glucose, glucose-6-phosphate, $\mathrm{KOH}$, imidazole, perchloric acid, and Tris-HCl, were purchased from Sigma (St. Louis, MO).

Animals. Male Sprague Dawley rats obtained from The University of Manitoba Central Animal Care breeding facility and weighing $210 \pm 20$ gm were used in the present studies. Before the start of the experiments, all animals were housed under a standard $12 \mathrm{hr}$ light/dark cycle (lights on at 6:00 A.M. and off at 6:00 P.M.). All protocols were performed in accordance with the guidelines set forth by the Canadian Council on Animal Care and were approved by the University of Manitoba Animal Care Ethics Committee.

Sleep deprivation. Sleep-deprivation experiments of 6, 12, and $24 \mathrm{hr}$ durations were started at 6:00 A.M. and were performed under lights-on conditions. Control animals for the sleep-deprivation studies were either handled while awake or left unattended; no significant differences in levels of brain glycogen were observed between these two groups of control animals. Rats were deprived of sleep by providing them with enriched environments and by gentle handling. At the end of the sleepdeprivation period, or in the case of one group $15 \mathrm{hr}$ after the termination of a $12 \mathrm{hr}$ sleep-deprivation period, rats were killed either by high energy $(10 \mathrm{~kW})$ focused microwave irradiation for $1.2 \mathrm{sec}$ or by perfusion fixation under general anesthesia. For microwaved rats, brain temperatures were determined directly after irradiation to ensure brains were $82 \pm 3^{\circ} \mathrm{C}$. After removal of brain, whole-brain or dissected-brain regions were frozen on dry ice and stored at $-80^{\circ} \mathrm{C}$ until taken for assay.

Tissue glycogen assays. Brain tissues were homogenized (Polytron; Kinematica, Kriens-Luzern, Switzerland; setting 6; $30 \mathrm{sec}$ ) in ice-cold $6 \%$ perchloric acid $(1: 5 \mathrm{w} / \mathrm{v})$ containing $1 \mathrm{~mm}$ EDTA. For measures of tissue glycogen content, glycogen was hydrolyzed to glucose in aliquots $(100 \mu \mathrm{l})$ of homogenate that were removed and incubated overnight (16 hr) at room temperature with $1 \mathrm{ml}$ of $0.2 \mathrm{M}$ sodium acetate, $20 \mu \mathrm{l}$ of 1.0 $\mathrm{M} \mathrm{KHCO}_{3}$, and $20 \mathrm{U} / \mathrm{ml}$ of amyloglucosidase. Adding $0.5 \mathrm{ml}$ of the perchloric acid solution stopped reactions. After centrifugation at $25,000 \times g$ for $10 \mathrm{~min}$ at $4^{\circ} \mathrm{C}$, supernatants were neutralized with a $\mathrm{KOH}$ solution consisting of (in $\mathrm{M}$ ): $3 \mathrm{KOH}, 0.3$ imidazole, and $0.4 \mathrm{KCl}$, centrifuged at $14,000 \times g$ for $10 \mathrm{~min}$ at $4^{\circ} \mathrm{C}$, and taken for assays of glucose content. For measures of endogenous glucose levels, nonhydrolyzed samples were obtained by centrifuging homogenates as described above and adjusting the $\mathrm{pH}$ of supernatants to a final $\mathrm{pH}$ of $6-8$ with the $\mathrm{KOH}$ solution. Neutralized samples were mixed thoroughly, centrifuged as described above, and assayed for endogenous (background) glucose levels. The assay for glucose content was performed in 96-well plates using a coupled enzyme assay method modified from Passonneau and Lauderdale (1974). To each well of the 96-well plate was added $200 \mu \mathrm{l}$ of a reaction solution containing $50 \mathrm{~mm}$ Tris- $\mathrm{HCl}, \mathrm{pH} 8.1,0.5 \mathrm{~mm}$ ATP, 0.5 $\mathrm{mm} \mathrm{NADP}^{+}, 5 \mathrm{mM} \mathrm{MgSO}_{4}$, and $0.1 \mathrm{U} / \mathrm{ml}$ glucose-6-phosphate dehydrogenase. The 96-well plates were placed in the fluorescence plate reader (SpectraMax Gemini; Molecular Devices, Menlo Park, CA) and shaken, and measurements of formed NADPH were taken at $355 \mathrm{~nm}$ excitation, 480 $\mathrm{nm}$ emission, and $420 \mathrm{~nm}$ cutoff wavelengths. After addition of hexokinase $(0.3 \mathrm{U})$ to each well, plates were shaken and measurements were taken after a 30 min incubation period. Tissue glycogen levels indicated as glucose units were calculated by subtracting the final micromolar concentration of glucose per gram of wet weight of the nonhydrolyzed tissue sample from the micromolar concentration of glucose per gram of wet weight of the hydrolyzed tissue sample.

Glycogen histochemistry. Rats either were anesthetized with sodium pentobarbital (50 mg/kg, i.p.) and killed by intracardiac perfusion of PBS containing $4 \%$ paraformaldehyde or were killed by focused high-energy microwave irradiation $(10 \mathrm{~kW} ; 1.2 \mathrm{sec})$. Rat brains were carefully removed and postfixed overnight in PBS containing $4 \%$ paraformaldehyde. For frozen sectioning, brains were placed in PBS containing $0.5 \mathrm{M}$ sucrose, $\mathrm{pH} 7.3$, at $4^{\circ} \mathrm{C}$ until buoyancy was lost. Eight micrometer sections were cut on a cryostat (Shandon-Lipshaw, Pittsburgh, PA) and mounted on silane-treated slides. For paraffin sections, brain samples were dehydrated through graded alcohol and embedded in paraffin (PolyFin; Triangle Biomedical Sciences, Durham, NC); sections were cut to a thickness of $6 \mu \mathrm{m}$, mounted onto silane-treated slides, dewaxed in xylene, and rehydrated. Glycogen was determined histochemically in all tissue sections using a periodic acid-Schiff's base (PAS) method after treatment with dimedone, an agent used to block aldehyde groups on nonglycogen substances such as connective tissue mucopolysaccharide and glycoprotein (Bulmer, 1959). Brain sections were oxidized with $0.5 \%$ periodic acid for $10 \mathrm{~min}$ at room temperature followed by exposure to a saturated solution of dimedone in distilled water for $20 \mathrm{~min}$ at $60^{\circ} \mathrm{C}$. After rinsing in distilled water, sections were reacted with Schiff's reagent prepared as described previously (McManus, 1946). The specificity of the dimedonePAS reaction was confirmed by digestion with diastase as described previously (Bulmer, 1959). The dimedone-PAS-stained sections were scanned directly into a computer with a CanoScan FS2710 (Canon Inc., Tokyo, Japan) slide scanner. To generate figures, representative images were arranged into montages using CorelDraw 9 (Corel Corporation Ltd., Ottawa, Canada). Digitized images were first converted to grayscale pictures and then measured against background levels using Scion software (Scion Corp., Frederick, MD). After background subtraction, integrated densities were determined from eight sections per rat; reported values are mean \pm SEM values from at least four rats per group. Statistical analyses were by ANOVA with Tukey's post-test.

Immunohistochemistry. Rat brain sections were blocked and permeabilized with PBS containing $2 \%$ BSA, $5 \%$ normal goat serum, and $0.3 \%$ Triton X-100 for $30 \mathrm{~min}$ at room temperature. The sections were then incubated with a monoclonal antibody against glial fibrillary acidic protein (GFAP; 1:200) and a rabbit antibody against neurofilament light subunit (NFL; 1:200) overnight at $4^{\circ} \mathrm{C}$ followed by rhodamine-conjugated goat anti-mouse and FITC-conjugated goat anti-rabbit antibodies (1:200) for $2 \mathrm{hr}$ at room temperature. Fluorescent pictures were taken on a Zeiss (Thornwood, NY) microscope equipped with an AxioCam digital camera (Carl Zeiss, Jena, Germany).

\section{RESULTS}

One of the great technical challenges that had to be overcome in these studies was determining methods by which levels of brain glycogen could be measured with precision and accuracy. We have shown previously that it is necessary to kill animals with focused high-energy microwave irradiation to obtain precise and accurate measurements in situ of cellular energy charge including adenine nucleotides and adenosine (Delaney and Geiger, 1996). For brain glycogen, measurements were made in discrete brain regions taken from animals killed using three power levels of microwave irradiation $(3.5 \mathrm{~kW}$ for $3.5 \mathrm{sec}, 6.0 \mathrm{~kW}$ for $2.1 \mathrm{sec}$, and $10 \mathrm{~kW}$ for $1.2 \mathrm{sec}$ ), because these were the levels of commercially available microwave killing systems; for comparison, measurements were also made in animals killed by decapitation. The microwave times were adjusted for each microwave power level to achieve brain temperatures of $85^{\circ} \mathrm{C}$. Levels of glycogen in the frontal cortex and hypothalamus of animals killed by decapitation were low ( $<0.4 \mu$ moles per gram of wet tissue) (Fig. 1). Maximum levels of glycogen in both brain regions were only observed when brains were heated to $82 \pm 3^{\circ} \mathrm{C}$ with $10 \mathrm{~kW}$ of focused microwave energy. Although $6 \mathrm{~kW}$ was adequate for accurate measures of glycogen in the hypothalamus, this power level was insufficient to heat brains quickly and evenly enough to snapinactivate glycogen-metabolizing enzymes in the frontal cortex; this difference was almost certainly attributable to the well known physical principal that microwave irradiation heats basal structures more quickly than dorsal structures. Even decapitation into liquid nitrogen was inadequate for accurate measures; levels of glycogen (micromoles per gram of wet weight) in the cerebellum of rats killed by decapitation with heads immediately frozen in liquid nitrogen $(1.8 \pm 0.6)$ were significantly $(p<0.05)$ lower than were levels of $5.3 \pm 0.4$ in the cerebellum of rats killed by microwaving at $10 \mathrm{~kW}$. Thus, microwave irradiation at $10 \mathrm{~kW}$ appears to provide for accurate and precise measurements of glycogen levels in discrete brain regions; as a result, $10 \mathrm{~kW}$ conditions were used in all of the remaining studies.

The hypothesis central to these studies is that increased wakefulness (sleep deprivation) would lead to a run-down of glycogen, the main energy store in brain. To test this hypothesis, rats were maintained, through the presentation of novel environments and gentle handling, in a constant state of wakefulness for 6,12 , or 24 $\mathrm{hr}$; control animals were allowed to sleep normally in an adjacent quiet room. Control animals were killed at the same time as 


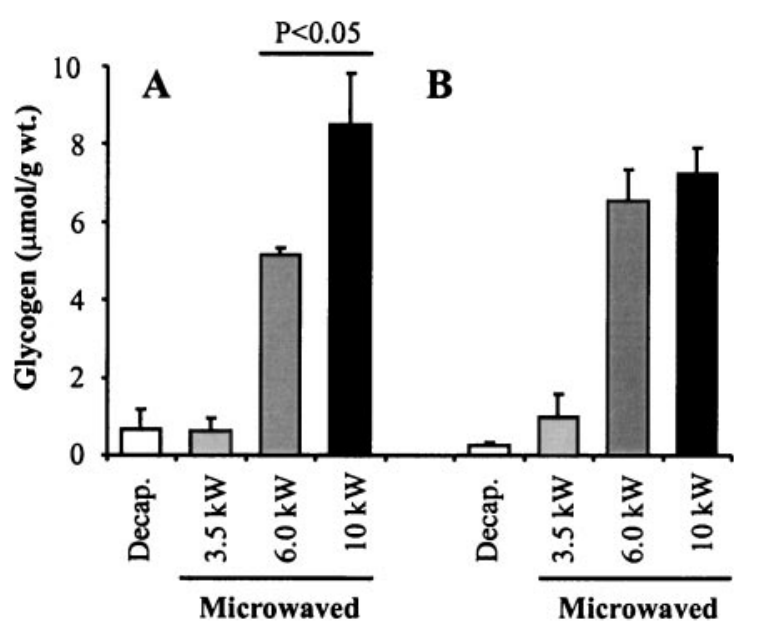

Figure 1. Male Sprague Dawley rats (8 in each group) were killed by focused microwave irradiation at three power levels $(3.5,6.0$, or $10 \mathrm{~kW})$ or by decapitation (Decap.). Irradiation times were adjusted for brains to be heated to $82 \pm 3^{\circ} \mathrm{C}$. Glycogen levels were determined for the frontal cortex $(A)$ and hypothalamus $(B)$. Values illustrated are mean \pm SEM values. Glycogen levels in the frontal cortex and hypothalamus of rats killed with 6.0 and $10 \mathrm{~kW}$ of microwave power were significantly ( $p<$ 0.001 ) higher than were levels in rats killed with $3.5 \mathrm{~kW}$ of microwave power or by decapitation. Glycogen levels in the frontal cortex of rats killed with $10 \mathrm{~kW}$ of microwave power were significantly $(p<0.05)$ higher than were levels in rats killed with $6.0 \mathrm{~kW}$ of microwave power.

experimental (i.e., sleep-deprived) animals. Brain levels of glycogen in rats killed with $10 \mathrm{~kW}$ of focused microwave irradiation were decreased significantly by $38 \%$ in $12 \mathrm{hr}(p<0.01)$ and by $38 \%$ in $24 \mathrm{hr}(p<0.001)$ sleep-deprived rats (Fig. $2 A)$. However, no statistically significant differences were observed between $6 \mathrm{hr}$ sleep-deprived rats and their control rats or between any of the groups of control rats (Fig. $2 A$ ).

If the sleep-deprivation-induced decreases in brain glycogen represented a rundown in brain energy metabolism as a result of prolonged wakefulness, then the decreases should be reversible after an adequate period of recovery sleep. Such a finding would be compatible with the hypothesis that depletion of glycogen is part of the homeostatic signal for sleep promotion and/or a consequence of the period of prolonged wakefulness. Accordingly, we tested the hypothesis that a $15 \mathrm{hr}$ period of recovery sleep directly after a 12 hr sleep-deprivation period would result in brain glycogen returning to control levels. As illustrated in Figure $2 B$, levels of brain glycogen after recovery sleep not only returned to control levels but also were increased significantly $(p<0.05)$ by $27 \%$.

To confirm and extend the findings that increased wakefulness causes a rundown in levels of brain glycogen, we determined the distribution of glycogen in rat brain sections using a modified PAS-dimedone histochemical method and compared the intensity of staining in brain sections obtained from control and sleepdeprived rats. The staining was specific for glycogen because dimedone, a compound that selectively blocks aldehyde groups on nonglycogen substances (Bulmer, 1959), and diastase, an enzyme that digests glycogen, reduced the staining dramatically (Fig. 3G). As reported previously (Leske and von Mayersbach, 1969), glycogen was fairly evenly distributed in paraffinembedded sections of perfusion-fixed brains (Fig. $3 A, B$ ). In contrast to paraffin sections, however, glycogen in cryostat sections taken from brains of rats killed by either perfusion-fixation (Fig. $3 E-G$ ) or by microwaving at $10 \mathrm{~kW}$ (Fig. 3C,D) was heterogeneously distributed throughout the brain, with the highest inten-
$\mathbf{A}$

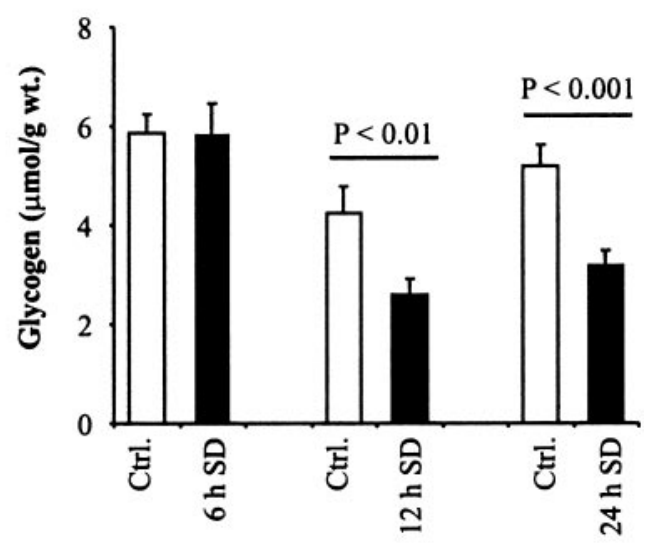

B

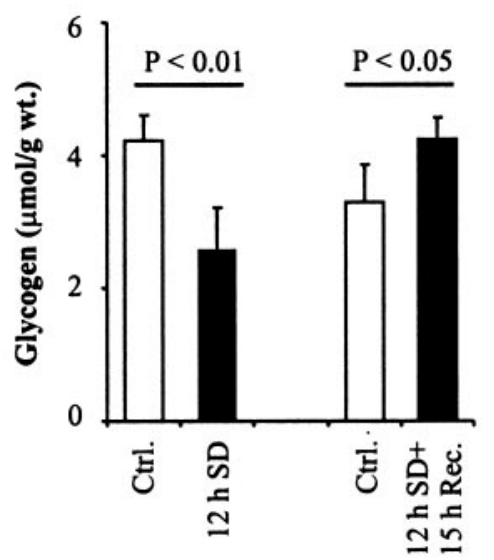

Figure 2. A, Male Sprague Dawley rats were deprived of sleep starting at 6:00 A.M. (lights on) for 6,12 , or $24 \mathrm{hr}$ and then killed by $10 \mathrm{~kW}$ of focused microwave irradiation. Glycogen levels were measured in the brain minus the cerebellum and brainstem of control (Ctrl.) and sleepdeprived $(S D)$ rats. Mean \pm SEM values from eight rats in each group are shown. Glycogen levels in control animals showed no statistically significant differences between the separate 6,12 , and $24 \mathrm{hr}$ studies. Statistically significant decreases in brain glycogen levels were observed with sleepdeprivation periods of $12(p<0.01)$ and $24(p<0.001) \mathrm{hr}$. B, Two separate groups of male Sprague Dawley rats were deprived of sleep for $12 \mathrm{hr}$ starting at 6:00 A.M. Rats in group 1 were killed by $10 \mathrm{~kW}$ of focused microwave irradiation after $12 \mathrm{hr}$ of sleep deprivation. Rats in group 2 were allowed recovery (Rec.) sleep in an isolated room for $15 \mathrm{hr}$ before being killed by $10 \mathrm{~kW}$ of focused microwave irradiation. Glycogen levels were measured in the brain minus the cerebellum and brainstem, and data shown are mean \pm SEM values from eight animals in each group. Statistically significant $(p<0.01)$ decreases in glycogen levels were observed with $12 \mathrm{hr}$ of sleep deprivation compared with control animals, whereas statistically significant $(p<0.05)$ increases in glycogen levels were observed with $15 \mathrm{hr}$ of recovery sleep after the $12 \mathrm{hr}$ sleep-deprivation period.

sity of staining being found in white matter and fiber tracts. The regional heterogeneity of glycogen levels as determined histochemically was verified by dissecting out specific brain regions from rats killed by $10 \mathrm{~kW}$ of microwave irradiation and measuring brain glycogen biochemically. As expected, the highest levels of glycogen were found in the corpus callosum (white matter); the levels in the cerebellum, cerebral cortex, brainstem, thalamus, and striatum were approximately three times lower than in the corpus callosum (Fig. 4A). To verify that this distribution pattern of glycogen matches with that of astrocyte density, brain sections were immunohistochemically stained with antibodies against GFAP, a marker of type 2 astrocytes, and the neuronal marker neurofilament light subunit. As expected, GFAP-positive cells 

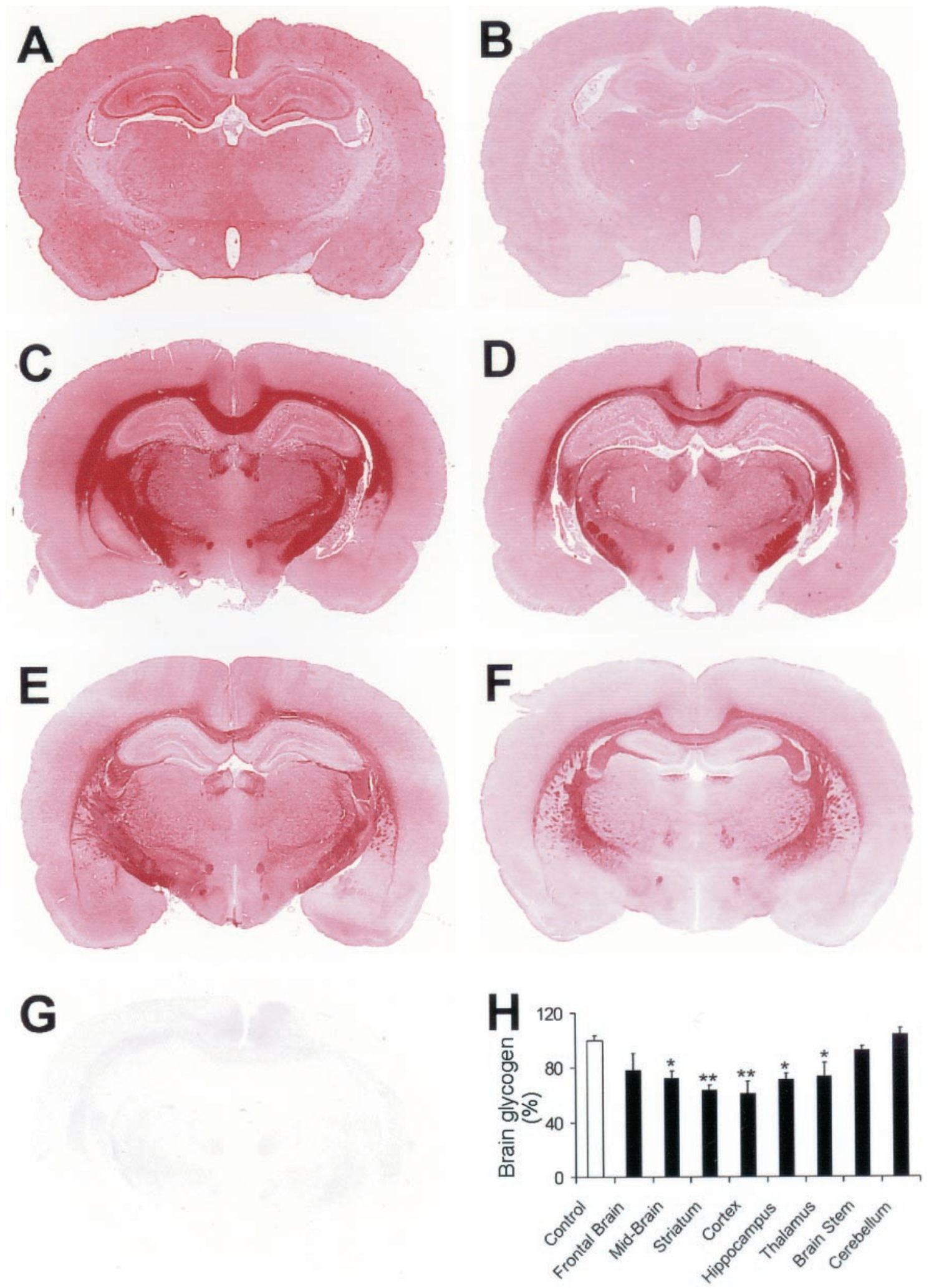

Figure 3. Histochemical determination of brain glycogen. Control rats $(A, C, E)$ and rats deprived of sleep for $12 \mathrm{hr}(B, D, F)$ were killed either by intracardial perfusion of $4 \%$ paraformaldehyde $(A, B, E-G)$ or by $10 \mathrm{~kW}$ of microwave irradiation $(C, D)$. For rats that were perfusion-fixed, brain sections were either cut using a cryostat $(C-G)$ or paraffin-embedded and cut using a microtome (RM2125RT; Leica, Nussloch, Germany) ( $A$, $B$ ). Regardless of method used to kill the animal and cut the tissue sections, all sections were processed and stained the same for PAS-dimedone histochemistry. $G$, Pretreatment of sections with diastase to digest glycogen yielded background staining from nonglycogen sources. $H$, Images were digitized and staining intensities were measured with Scion software. Each group consisted of four rats. Values are mean \pm SEM from eight separate sections per animal $\left({ }^{*} p<0.05 ; * *<0.01\right)$. 
A

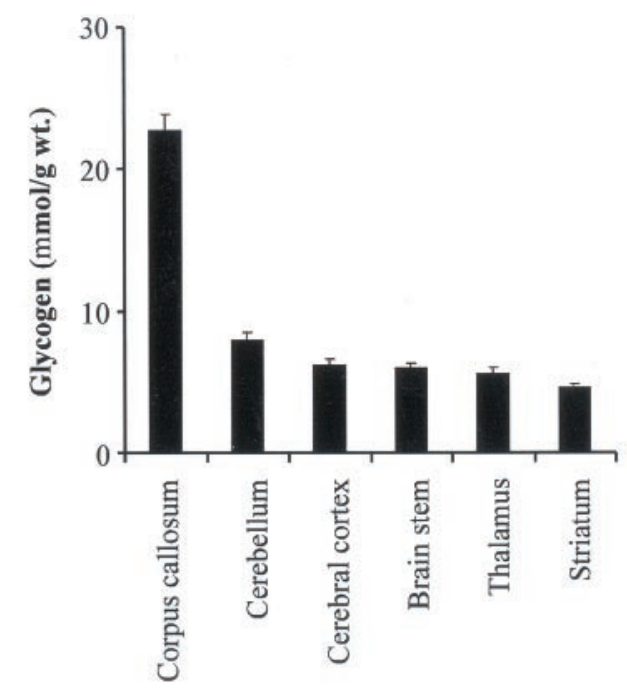

$\mathbf{B}$

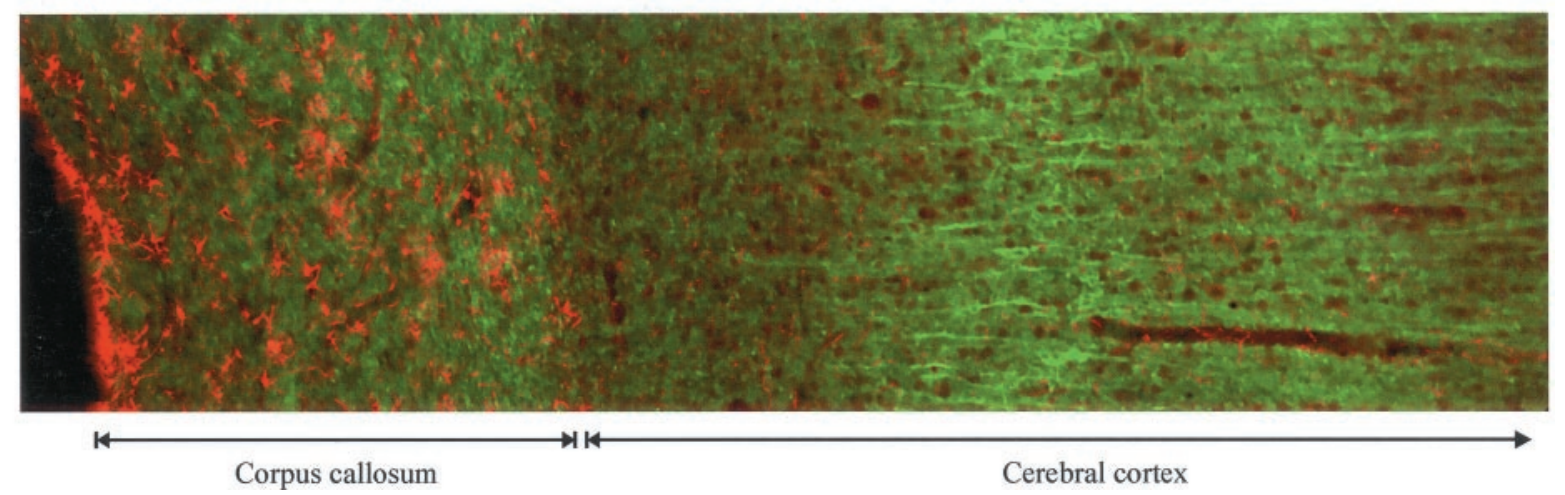

Figure 4. Codistribution of brain glycogen and astrocytes. $A$, Glycogen is enriched in white matter. Brain regions were dissected from rats killed by 10

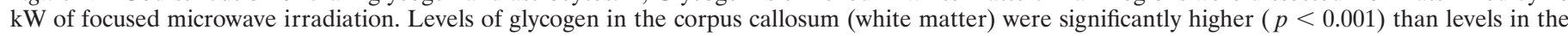

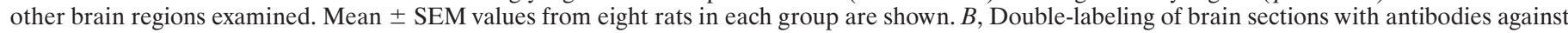
GFAP and NFL revealed that astrocytes were distributed throughout the brain but were concentrated in white matter.

were found throughout the brain but were enriched in the corpus callosum (Fig. 4B) and other white matter areas (data not shown).

Regardless of the method of killing or sectioning, glycogen staining in $12 \mathrm{hr}$ sleep-deprived rats was decreased significantly (Fig. 3B,D,F) compared with controls. When specific areas of brain sections were digitized and analyzed, we found significant decreases $(p<0.01)$ of $38 \%$ in the cortex, $36 \%$ in the striatum, $28 \%$ in the hippocampus, and $26 \%$ in the mid-brain and thalamus. The decreases in glycogen were not uniform throughout the brain; the brain stem and cerebellum showed no statistically significant differences between control and sleep-deprived rats (Fig. $3 H$ ). Measurement of the heavily stained white matter and nerve bundles showed significant decreases of $36 \%$ in the cortex, $42 \%$ in the striatum, and $50 \%$ in the thalamus; no statistically significant differences were found in the white matter of the brain stem and cerebellum. Although not illustrated, the sleepdeprivation-induced decreases in glycogen were also observed when brain regions from control and sleep-deprived rats were embedded in one block, thereby ensuring that the sectioning, mounting on slides, staining, and quantification were consistent.

We subsequently tested the hypothesis that a $15 \mathrm{hr}$ period of recovery sleep was sufficient to normalize sleep-deprivationinduced decreases in glycogen in both the gray and white matter.
As expected, the staining for glycogen was heterogeneously distributed and enriched in white matter in control rats (Fig. 5A) and was decreased significantly in rats deprived of sleep for $12 \mathrm{hr}$ (Fig. $5 B)$. After $15 \mathrm{hr}$ of recovery sleep, the decreased levels observed in $12 \mathrm{hr}$ sleep-deprived rats were not only reversed but were increased slightly by $9 \%$ compared with control rats; the increase above control levels was not statistically significant (Fig. 5C,D). The normalization of staining for glycogen to control levels with recovery sleep was approximately equal for gray and white matter.

During periods of sleep deprivation, rats become hyperphagic but nevertheless lose weight (Rechtschaffen et al., 1983). In our experiments, rats lost $\sim 8 \%$ of their body weight during a $12 \mathrm{hr}$ sleep-deprivation period. To rule out the possibility that the decreases in brain glycogen with sleep deprivation were caused by an overall imbalance between energy supply and demand, we measured brain glycogen levels in five brain regions taken from four control rats and four rats deprived of food for $12 \mathrm{hr}$. No statistically significant differences in brain glycogen levels were observed between the two groups of rats (Table 1). Furthermore, in our studies the levels of glucose in nonhydrolyzed samples from $12 \mathrm{hr}$ sleep-deprived rats were not significantly different from control rats (data not shown). These results are consistent with previous findings that levels of blood glucose were unaf- 

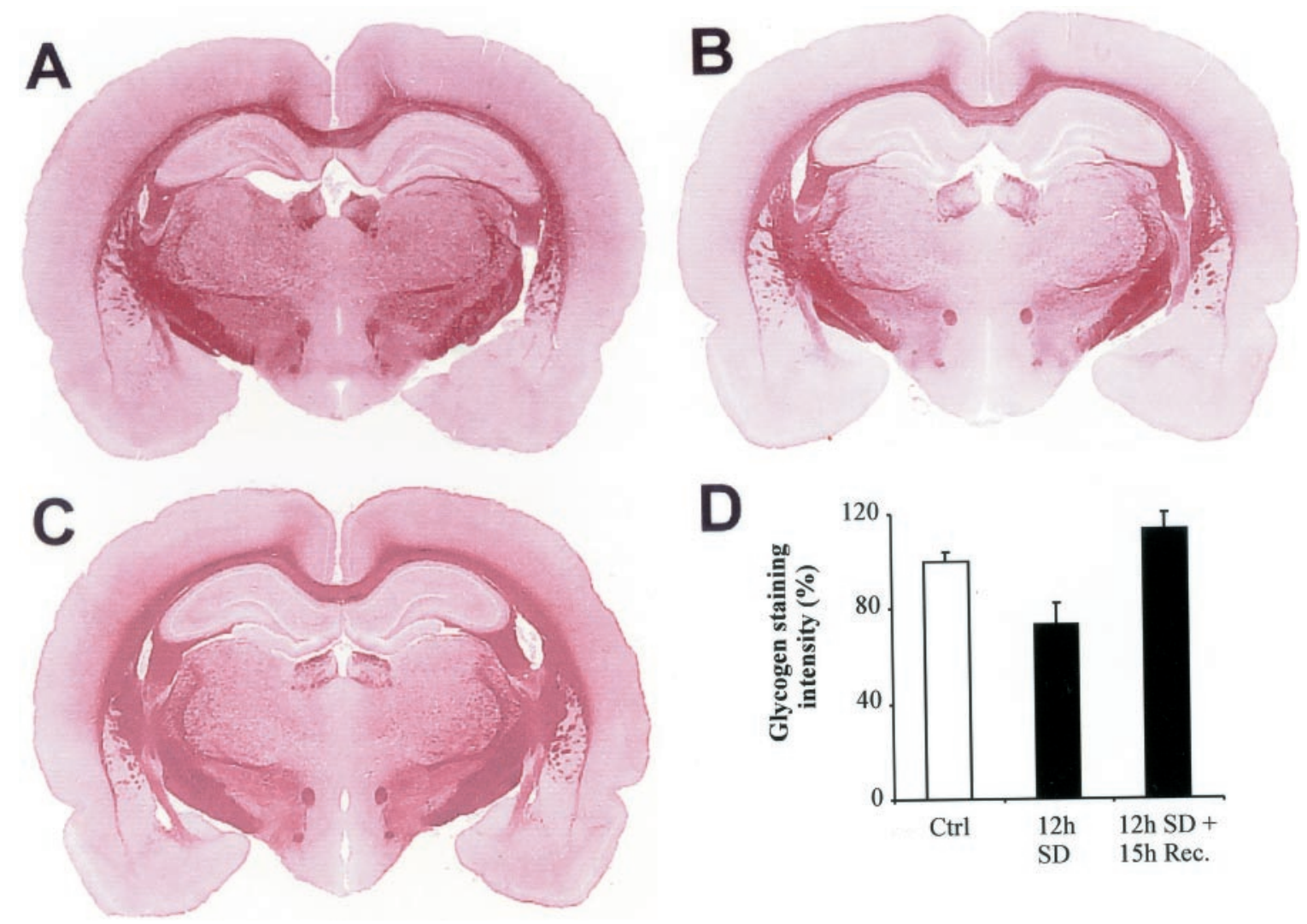

Figure 5. Histochemical determination of brain glycogen in control $(C t r l)$ rats $(A)$, rats that were deprived of sleep $(S D)$ for 12 hr $(B)$, and rats that were deprived of sleep for $12 \mathrm{hr}$ followed by $15 \mathrm{hr}$ of recovery (Rec.) sleep $(C)$. All rats were perfusion-fixed, and brain sections were cut using a cryostat. Images were digitized, staining intensities were measured with Scion, and values shown are mean \pm SEM from four rats $(p<0.01$ compared with control values).

$\overline{\text { Table 1. Effect of starvation on brain glycogen (micromoles per gram of }}$ wet weight tissue)

\begin{tabular}{lll} 
Brain region & Control & Starvation \\
\hline Striatum & $3.1 \pm 0.2$ & $3.5 \pm 0.2$ \\
Cortex & $3.6 \pm 0.2$ & $4.2 \pm 1.2$ \\
Thalamus & $3.2 \pm 0.2$ & $2.7 \pm 0.3$ \\
Brain Stem & $4.0 \pm 1.0$ & $4.1 \pm 0.3$ \\
Cerebellum & $3.2 \pm 0.4$ & $4.0 \pm 0.1$
\end{tabular}

$\overline{\text { Brain levels of glycogen were not affected by starvation. Male Sprague Dawley rats }}$ were starved for $12 \mathrm{hr}$ starting at 6:00 P.M. (lights out) and killed at 6:00 A.M. by 10 $\mathrm{kW}$ of focused microwave irradiation. Glycogen levels were measured in isolated brain regions and data are mean \pm SEM values from four animals in each group.

fected by $12 \mathrm{hr}$ of sleep deprivation, and that a $24 \mathrm{hr}$ starvation period was required before significant decreases were observed in levels of brain glycogen and glucose (Garriga and Cusso, 1992).

\section{DISCUSSION}

Considerable uncertainty continues to exist as to the nature of sleep drive. Our results indicating that sleep deprivation results in significant decreases in levels of brain glycogen provide a critical test of the hypothesis of Benington and Heller (1995), which posited that with sleep deprivation, wakefulness-induced stimulation of monoaminergic receptor systems would result in increased glycogenolysis and decreased levels of brain glycogen. Although at present untested, the decrease in the principal energy store in the brain (glycogen) might then lead to a state of bioenergetic stress whereby levels of ATP would be decreased and levels of the sleep-promoting substance adenosine would be increased. The decreases in glycogen observed here were almost certainly the result of increased sleep need, because with recovery sleep the decreases were not only reversed but also were increased above control levels. The physiological implications of such an overshoot in brain glycogen might be similar to that found in muscles after submaximal exercise (Bergstrom and Hultman, 1966; Robinson et al., 1999) and may relate to the ability of the brain to compensate for or "train" itself against the possibility of repeated bouts of sleep deprivation. Furthermore, the decreases in levels of glycogen with sleep deprivation were unlikely to be caused by "handling stress," because levels of glycogen were not different between control rats and rats that were handled for $6 \mathrm{hr}$ (Fig. $2 A$ ) or $12 \mathrm{hr}$ (data not shown).

It has been a technical challenge to accurately measure brain glycogen concentration, because brain glycogen is low and metabolized rapidly during ischemia. The current optimal method is to snap-inactivate glycogen-metabolizing enzymes using focused microwave irradiation. In the present study, we used a power level of $10 \mathrm{~kW}$ for $1.2 \mathrm{sec}$, the highest power level commercially available, to kill animals. Our results showed that irradiation at a higher energy level $(10 \mathrm{~kW})$ not only shortened the time needed to inactivate enzymes but also heated the brain more thoroughly, because $6 \mathrm{~kW}$ for $2.1 \mathrm{sec}$ was not sufficient to evenly heat the whole rat brain (Fig. $1 A$ ).

Levels of brain glycogen may vary with the functional status of the animal (for example, at different times of day), and glycogen measurements may be affected by the reagents used. Therefore, sleep deprivation and control experiments were performed in 
tandem in the present study. However, variance in glycogen measurements may still result from tissue sampling because of the heterogeneity of astrocyte distribution in the brain (J. Kong and J. D. Geiger, unpublished observation).

Brain energy metabolism relies on astrocytes (Tsacopoulos and Magistretti, 1996; Magistretti et al., 1999; Ames, 2000), and glycogen turnover in the brain is enhanced when adjacent neural activity is increased (Orkand et al., 1973; Swanson, 1992). Astrocytes uptake glucose from the blood, synthesize it into glycogen, and are the principal storage sites for glycogen in brain. During periods of increased neuronal activity such as occurs during waking, a number of neurotransmitters including norepinephrine, serotonin, and histamine, are released (Challet et al., 2001; Huang et al., 2001; Lai et al., 2001), and the resulting glycogenolysis leads to the increased release of lactate that is then available for use by neurons as a metabolic substrate (Dringen et al., 1993). Thus, astrocytes play a central role in brain energy metabolism (Tsacopoulos and Magistretti, 1996; Magistretti et al., 1999), and the glycogen stores in these cells may play an important role in balancing energy expenditure with requirements to replenish these stores.

Our finding that glycogen is more abundant in brain white matter is consistent with the distribution of glycogen-containing type 2 astrocytes (Savchenko et al., 2000). This distribution pattern of glycogen is probably of functional significance because $\sim 30 \%$ of brain energy expenditure occurs in white matter for axonal and dendritic transport, glycogen is a source of glucose during transient increases in metabolic demand (Pellerin et al., 1998), and glycogenolysis can be initiated more rapidly than increased transport of glucose from plasma (Dringen et al., 1993; Ames, 2000). Therefore, glycogen utilization may occur where and when it is important, especially during the first critical moments of stimulation. Sleep deprivation decreased glycogen in gray and white matter equally, and the levels recovered to above normal levels with rebound sleep. It is therefore tempting to speculate that glycogen is involved in the powerful homeostatic drive to sleep. Furthermore, the glycogen localized to white matter may play an important role in shaping normal operations of brain circuitry and in ensuring optimal neuronal responsiveness.

\section{REFERENCES}

Ames III A (2000) CNS energy metabolism as related to function. Brain Res Brain Res Rev 34:42-68.

Basheer R, Rainnie DG, Porkka Heiskanen T, Ramesh V, McCarley RW (2001) Adenosine, prolonged wakefulness, and A1-activated NF- $\kappa$ B DNA binding in the basal forebrain of the rat. Neuroscience 104:731-739.

Benington JH, Heller HC (1995) Restoration of brain energy metabolism as the function of sleep. Prog Neurobiol 45:347-360.

Bergstrom J, Hultman E (1966). Muscle glycogen synthesis after exercise: an enhancing factor localized to the muscle cells in man. Nature 210:309-310.

Bulmer D (1959) Dimedone as an aldehyde blocking reagent to facilitate the histochemical demonstration of glycogen. Stain Technol 34:95-98.

Challet E, Turek FW, Laute M, Van Reeth O (2001) Sleep deprivation decreases phase-shift responses of circadian rhythms to light in the mouse: role of serotonergic and metabolic signals. Brain Res 909:81-91.

Delaney SM, Geiger JD (1996) Brain regional levels of adenosine and adenosine nucleotides in rats killed by high-energy focused microwave irradiation. J Neurosci Methods 64:151-156.

Dringen R, Gebhardt R, Hamprecht B (1993) Glycogen in astrocytes: possible function as lactate supply for neighboring cells. Brain Res 623:208-214

Drummond SP, Brown GG, Gillin JC, Stricker JL, Wong EC, Buxton RB (2000) Altered brain response to verbal learning following sleep deprivation. Nature 403:655-657.

Franken P, Dijk DJ, Tobler I, Borbely AA (1991) Sleep deprivation in rats: effects on EEG power spectra, vigilance states, and cortical temperature. Am J Physiol 261:R198-R208.

Franken P, Chollet D, Tafti M (2001) The homeostatic regulation of sleep need is under genetic control. J Neurosci 21:2610-2621.
Garriga J, Cusso R (1992) Effect of starvation on glycogen and glucose metabolism in different areas of the rat brain. Brain Res 591:277-282.

Hendricks JC, Finn SM, Panckeri KA, Chavkin J, Williams JA, Sehgal A, Pack AI (2000) Rest in Drosophila is a sleep-like state. Neuron 25:129-138.

Horne JA (1985) Sleep function, with particular reference to sleep deprivation. Ann Clin Res 17:199-208.

Huang ZL, Qu WM, Li WD, Mochizuki T, Eguchi N, Watanabe T, Urade Y, Hayaishi O (2001) Arousal effect of orexin A depends on activation of the histaminergic system. Proc Natl Acad Sci USA 98:9965-9970.

Karnovsky ML, Reich P, Anchors JM, Burrows BL (1983) Changes in brain glycogen during slow-wave sleep in the rat. J Neurochem 41:1498-1501.

Koizumi J (1974) Glycogen in the central nervous system. Prog Histochem Cytochem 6:1-37.

Lai YY, Kodama T, Siegel JM (2001) Changes in monoamine release in the ventral horn and hypoglossal nucleus linked to pontine inhibition of muscle tone: an in vivo microdialysis study. J Neurosci 21:7384-7391.

Leske R, von Mayersbach H (1969) The role of histochemical and biochemical preparation methods for the detection of glycogen. J Histochem Cytochem 17:527-538.

Magistretti PJ, Pellerin L (1996) Cellular bases of brain energy metabolism and their relevance to functional brain imaging: evidence for a prominent role of astrocytes. Cereb Cortex 6:50-61.

Magistretti PJ, Pellerin L (1999) Cellular mechanisms of brain energy metabolism and their relevance to functional brain imaging. Philos Trans R Soc Lond B Biol Sci 354:1155-1163.

Magistretti PJ, Pellerin L, Rothman DL, Shulman RG (1999) Energy on demand. Science 283:496-497.

McManus J (1946) Histological demonstration of mucin after periodic acid. Nature 158:202.

Orkand PM, Bracho H, Orkand RK (1973) Glial metabolism: alteration by potassium levels comparable to those during neural activity. Brain Res 55:467-471.

Passonneau JV, Lauderdale VR (1974) A comparison of three methods of glycogen measurement in tissues. Anal Biochem 60:405-412.

Pellerin L, Pellegri G, Bittar PG, Charnay Y, Bouras C, Martin JL, Stella N, Magistretti PJ (1998) Evidence supporting the existence of an activity-dependent astrocyte-neuron lactate shuttle. Dev Neurosci 20:291-299.

Pentreath V, Kai-Kai M (1982) Significance of the potassium signal from neurons to glial cells. Nature 295:59-61.

Phelps CH (1972) Barbiturate-induced glycogen accumulation in brain. An electron microscopic study. Brain Res 39:225-234.

Porkka Heiskanen T, Strecker RE, Thakkar M, Bjorkum AA, Greene RW, McCarley RW (1997) Adenosine: a mediator of the sleepinducing effects of prolonged wakefulness. Science 276:1265-1268.

Porkka Heiskanen T, Strecker RE, McCarley RW (2000) Brain sitespecificity of extracellular adenosine concentration changes during sleep deprivation and spontaneous sleep: an in vivo microdialysis study. Neuroscience 99:507-517.

Rainnie DG, Grunze HC, McCarley RW, Greene RW (1994) Adenosine inhibition of mesopontine cholinergic neurons: implications for EEG arousal. Science 263:689-692.

Rechtschaffen A, Gilliland MA, Bergmann BM, Winter JB (1983) Physiological correlates of prolonged sleep deprivation in rats. Science 221:182-184.

Robinson TM, Sewell DA, Hultman E, Greenhaff PL (1999) Role of submaximal exercise in promoting creatine and glycogen accumulation in human skeletal muscle. J Appl Physiol 87:598-604.

Savchenko V, McKanna JA, Nikonenko IR, Skibo GG (2000) Microglia and astrocytes in the adult rat brain: comparative immunocytochemical analysis demonstrates the efficacy of lipocortin 1 immunoreactivity. Neuroscience 96:195-203.

Shaw PJ, Cirelli C, Greenspan RJ, Tononi G (2000) Correlates of sleep and waking in Drosophila melanogaster. Science 287:1834-1837.

Sloane JA, Hollander W, Rosene DL, Moss MB, Kemper T, Abraham CR (2000) Astrocytic hypertrophy and altered GFAP degradation with age in subcortical white matter of the rhesus monkey. Brain Res 862:1-10.

Swanson RA (1992) Physiologic coupling of glial glycogen metabolism to neuronal activity in brain. Can J Physiol Pharmacol [Suppl] 70:S138-S144.

Swanson RA, Sagar SM, Sharp FR (1989) Regional brain glycogen stores and metabolism during complete global ischaemia. Neurol Res $11: 24-28$

Tsacopoulos M, Magistretti PJ (1996) Metabolic coupling between glia and neurons. J Neurosci 16:877-885.

Wender R, Brown AM, Fern R, Swanson RA, Farrell K, Ransom BR (2000) Astrocytic glycogen influences axon function and survival during glucose deprivation in central white matter. J Neurosci 20:68046810 . 